\title{
The Precarious Health of Young Mexican American Men in South Texas, Cameron County Hispanic Cohort, 2004-2015
}

\author{
Gordon P. Watt; Kristina P. Vatcheva, PhD; Derek M. Griffith, PhD; \\ Belinda M. Reininger, DrPH; Laura Beretta, PhD; Michael B. Fallon, MD; \\ Joseph B. McCormick, MD; Susan P. Fisher-Hoch, MD
}

\begin{abstract}
Suggested citation for this article: Watt GP, Vatcheva KP, Griffith DM, Reininger BM, Beretta L, Fallon MB, et al. The Precarious Health of Young Mexican American Men in South Texas, Cameron County Hispanic Cohort, 2004-2015. Prev Chronic Dis 2016;13:160020. DOI: http://dx.doi.org/10.5888/ pcd13.160020.
\end{abstract}

\section{PEER REVIEWED}

\section{Abstract}

\section{Introduction}

Hispanic men have higher rates of illness and death from various chronic conditions than do non-Hispanic men. We aimed to characterize the health of Mexican American men living on the US-Mexico border in South Texas and elucidate indications of chronic disease in young men.

\section{Methods}

We sampled all male participants from the Cameron County Hispanic Cohort, an ongoing population-based cohort of Mexican Americans in Brownsville, Texas. We calculated descriptive statistics and stratified the sample into 3 age groups to estimate the prevalence of sociodemographic, behavioral, and clinical factors by age group and evaluated differences between age groups.

\section{Results}

Obesity prevalence was approximately $50 \%$ across all age groups $(P=.83)$. Diabetes prevalence was high overall $(26.8 \%)$, and $16.9 \%$ (95\% confidence interval [CI], $10.1 \%-23.8 \%)$ of men younger than 35 had diabetes. More than $70 \%$ of these young men had elevated liver enzymes, and mean values of aspartate aminotransferase were significantly higher in younger men $(45.0 \mathrm{u} / \mathrm{L}$; $95 \% \mathrm{CI}, 39.5-50.6 \mathrm{u} / \mathrm{L}$ ) than in both older age groups. Less than
$20 \%$ of young men had any form of health insurance. Current smoking was higher in young men than in men in the other groups, and the rate was higher than the national prevalence of current smoking among Hispanic men.

\section{Conclusions}

We suggest a need for obesity and diabetes prevention programs and smoking cessation programs for men in this region. Opportunities exist to expand current intervention programs and tailor them to better reach this vulnerable population of young Hispanic men. Elevated liver enzymes in men younger than 35 suggest a substantial burden of liver abnormalities, a finding that warrants further study.

\section{Introduction}

Hispanic men comprise a rapidly growing demographic of the United States, yet the research literature on Hispanic men's health is sparse. Studies indicate that Hispanics in the United States face many health inequities, ranging from lack of access to care to higher rates of infectious and chronic diseases (1-4). However, few studies have addressed health inequalities in Hispanic men $(3,4)$. Despite having a longer life expectancy than non-Hispanic white men (5), Hispanic men have higher mortality rates than do non-Hispanic men for chronic conditions such as type 2 diabetes, end-stage renal disease, colorectal cancer (6), and liver disease (7). Research suggests that a lack of access to care contributes to this increased risk of death from chronic conditions in Hispanic men (8).

Hispanic men are an epidemiologically heterogeneous group. Improvements in Hispanic health surveillance data (9) and data from the Hispanic Community Health Study/Study of Latinos (HCHS/ SOL) and others indicate disparate health outcomes in Hispanics by ethno-regional subgroup $(3,10,11)$. However, to date, studies 
that examined the health of Hispanic ethnic subgroups in the United States neglect men's health; of the 37 publications that emerged from the HCHS/SOL, none specifically studied men's health (12). As an additional illustration of the dearth of health research in US Hispanic men, a 2016 MeSH term search of "men's health" and "Hispanic Americans or Mexican Americans" on Ovid Medline yielded only 20 relevant articles since 1946.

This study describes the health characteristics of Mexican American men on the southern Texas-Mexico border in Brownsville, Texas. This area is resource-poor, among the poorest cities in the United States (13). With a population of primarily Mexican descent (93.2\% Hispanic, of whom $86.2 \%$ are of Mexican descent), data from this ethnically homogenous population of men are ideal for comparing with those of nationwide surveys of Mexican American men's health (such as the National Health and Nutrition Examination Survey and HCHS/SOL). We have shown that this population has high rates of obesity, insulin resistance, diabetes, liver disease, and subclinical atherosclerosis, with significant differences by sex (14-19). Additionally, in reviewing the data from the Cameron County Hispanic Cohort (CCHC), a populationbased cohort study of the region, we observed high rates of obesity in younger men (younger than 35 years). The purpose of this study is to further characterize men's health by age group to assess the burden of chronic disease in younger men. Age is a relevant trait for risk stratification and intervention, and a precise characterization of the population is fundamental to any further work in Mexican American men.

\section{Methods}

We conducted a cross-sectional analysis of 945 men in the CCHC from Brownsville, Texas, recruited from 2004 through 2015. The $\mathrm{CCHC}$ is a representative sample of the Mexican American population in South Texas, selected by a 2-stage methodology using US Census data; socioeconomic quartiles are the sampling strata, and census blocks are the randomized sampling units. We invited all members (aged 18 years or older) of all households in the selected blocks to participate in the CCHC. Participants gave informed consent and then came to the local clinical research unit where extensive sociodemographic, clinical, and laboratory data were collected. We have detailed these protocols previously $(14,15)$. Trained bilingual health workers conducted a clinical exam and health interview in the participants' language of preference (English or Spanish). Participants arrived fasting for 10 hours so that blood samples could be obtained for a comprehensive metabolic panel, complete blood count with differential, and hemoglobin A1c (HbA1c) measurements. The study team measured anthropometrics and blood pressure and asked participants a range of demographic, clinical, health care use, and health behavior questions.

\section{Definitions}

The definition of elevated liver function tests (LFTs) was alanine transaminase (ALT) levels greater than $40 \mathrm{u} / \mathrm{L}$ and/or aspartate aminotransferase (AST) levels greater than $37 \mathrm{u} / \mathrm{L}$. We used the 2010 American Diabetes Association diagnostic criteria for diabetes mellitus (DM) (20). A body mass index (BMI) of more than $30 \mathrm{~kg} / \mathrm{m}^{2}$ indicated obesity. We defined hypertension as mean systolic blood pressure (SBP) at or above $130 \mathrm{~mm} \mathrm{Hg}$ or a mean diastolic blood pressure (DPB) at or above $85 \mathrm{~mm} \mathrm{Hg}$, or taking antihypertensive medication. Three or more of the following constituted metabolic syndrome: hypertension, triglyceride levels over $150 \mathrm{mg} / \mathrm{dL}$, high-density lipoprotein (HDL) cholesterol levels less than $40 \mathrm{mg} / \mathrm{dL}$, fasting blood glucose over $100 \mathrm{mg} / \mathrm{dL}$ or taking hypoglycemic medication, or waist circumference higher than 102 $\mathrm{cm}$ (21). Total cholesterol of more than $200 \mathrm{mg} / \mathrm{dL}$ indicated hypercholesterolemia. A "heavy drinker" was any participant reporting drinking more than 14 alcoholic drinks per week (22). We defined history of smoking as an affirmative response to the question, "Have you ever smoked more than 100 cigarettes in your entire life?" and current smoking as an affirmative response to the question, "Do you now smoke cigarettes?" among those with a history of smoking.

\section{Statistical methods}

The CCHC has a 2-stage population-based sampling methodology. To address possible sampling bias, we adjusted all analyses for the probability of sampling using age- and sex-adjusted sampling weights, based on the population of Brownsville, Texas. We also accounted for the potential clustering effect among participants from the same household or census block. We considered results statistically significant at $P<.05$. In descriptive analyses, we calculated unweighted frequencies and weighted proportions for categorical variables. We then stratified participants into 3 age groups (younger, aged 18-34 years; middle-aged, 35-54 years; and older, aged $\geq 55$ years) to estimate health outcomes by age group. Weighted proportions of participants in each age group were approximately equal (Rao-Scott $\chi^{2}=1.3, P=.53$ ).

We used the Rao-Scott $\chi^{2}$ test to assess equality of proportions of categorical variables across age groups. For continuous variables, we used survey-weighted linear regression analysis to detect differences in mean values across age groups. For blood pressure analysis, we adjusted for current antihypertensive medication, and

\footnotetext{
The opinions expressed by authors contributing to this journal do not necessarily reflect the opinions of the U.S. Department of Health and Human Services, the Public Health Service, the Centers for Disease Control and Prevention, or the authors' affiliated institutions.
} 
for analyses of triglycerides and LDL and HDL cholesterol variables, we adjusted for lipid-controlling medications. Because this population is binational, we sought to rule out confounding of place of birth on the results; using logistic and linear regression, we repeated each analysis controlling for place of birth. Where the adjustment for place of birth affected results, we have noted this effect; otherwise, crude results are presented.

In the case of a significant independent overall association of age with the variable of interest, we used multiple comparisons techniques to detect significant differences in the younger age group compared with the other age groups. For categorical associations, we used logistic regression to calculate odds ratios (ORs) for the outcome of interest in the younger age group compared with the other age groups. For significant associations with continuous variables, we applied regression models to obtain $t$-test results with Bonferroni-adjusted $P$ values for multiple pairwise comparisons across age groups; we reported the difference of least square means and associated 95\% confidence intervals (CIs) and $P$ values. For all analyses, we used SAS version 9.4 (SAS Institute, Inc).

\section{Results}

\section{Characteristics of the study population}

We excluded 86 participants who were missing critical data; our final sample was 945 men from the CCHC. Mean age of participants was 44.3 years, and approximately half $(50.4 \%)$ were born in Mexico (Table 1). The mean age of men born in the United States (40.4 y) was significantly lower than the mean age of men born outside the United States ( 48.0 y, $P=.002$; data not shown). Confounding by place of birth was significant for only one analysis: multiple comparisons of AST levels. The remaining results were not significantly affected when adjusting for place of birth, so crude results are presented. Most participants (63.6\%) had no medical insurance (including Medicare and Medicaid), and 18.9\% were unemployed (not retired) at the time of the interview. Many participants (38.5\%) declined to provide income data. Approximately half of the participants had a history of smoking (54.2\%), and $28.4 \%$ were current smokers. With regard to drinking habits, $7.3 \%$ reported heavy drinking, and $60.3 \%$ reported occasional alcohol consumption. We found high rates of metabolic abnormalities: $49.9 \%$ of participants were obese, $26.8 \%$ had diabetes, $44.0 \%$ met the criteria for metabolic syndrome, and $64.4 \%$ had elevated liver enzymes (Table 1).

\section{Stratified and multiple comparisons analyses}

Obesity prevalence was similar across age groups, at approximately $50 \%(P=.83)$ (Table 2$)$. Mean waist circumference $(P=.29)$ and mean BMI $(P=.19)$ were also similar across age groups. The proportion with diabetes was significantly associated with age group $(P<.001)$. This proportion was highest in the older age group (38.2\%; 95\% CI, 29.3\%-47.1\%), although $16.9 \%$ (95\% CI, $10.1 \%-23.8 \%$ ) of the younger age group had diabetes. Additionally, $51.3 \%$ (95\% CI, $42.9 \%-59.8 \%$ ) of men in the younger group had either prediabetes or diabetes, and this prevalence was even higher in the other 2 age groups (Figure 1).

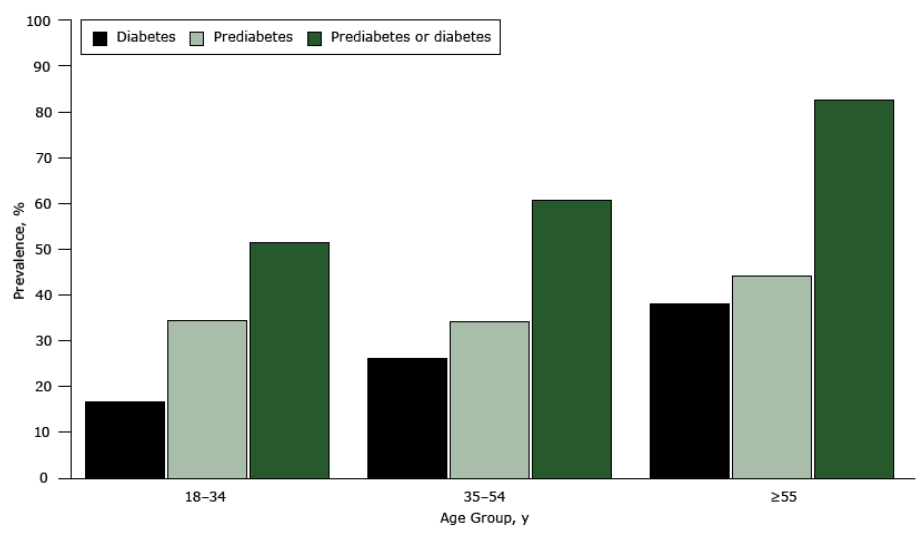

Figure 1. Proportion of male participants with diabetes, prediabetes, and prediabetes or diabetes, by age group, Cameron County Hispanic Cohort, 2004-2015. This figure shows that prevalence of prediabetes is above 30\% across age groups and that more than $50 \%$ of men younger than 35 years in this population have either diabetes or prediabetes.

The proportion of men with elevated LFTs was significantly associated with age group $(P=.001)$. In multiple comparisons analysis, the odds of elevated LFTs was significantly lower in the older age group than in the younger age group $(\mathrm{OR}=0.4 ; 95 \% \mathrm{CI}$, $0.3-0.8)$. When examining continuous values of ALT and AST, we found differences in both mean ALT $(P<.001)$ and mean AST $(P=.002)$ across age groups (Figure 2$)$. In multiple comparisons (Table 3), both ALT and AST mean levels were significantly higher in the younger group than in the older group (ALT difference: $17.2 \mathrm{u} / \mathrm{L} ; 95 \% \mathrm{CI}, 7.4-27.0 ; P<.001$; AST difference: $11.2 \mathrm{u} / \mathrm{L}$; $95 \% \mathrm{CI}, 3.7-18.7 ; P=.001)$. AST mean levels were also significantly higher in the younger group than in the middle-aged group (difference: $7.1 \mathrm{u} / \mathrm{L} ; 95 \% \mathrm{CI}, 0.02-14.1 ; P=.05$ ), but this finding did not remain significant when controlling for place of birth. There was an overall association between elevated triglycerides and age group $(P=.01)$. Multiple comparisons indicated that the odds of elevated triglycerides was significantly higher in the

\footnotetext{
The opinions expressed by authors contributing to this journal do not necessarily reflect the opinions of the U.S. Department of Health and Human Services, the Public Health Service, the Centers for Disease Control and Prevention, or the authors' affiliated institutions.
} 
middle-aged group than in the younger group $(\mathrm{OR}=2.2 ; 95 \% \mathrm{CI}$, 1.4-3.4), as were mean levels of triglycerides (difference: -48.4 $\mathrm{mg} / \mathrm{dL}, 95 \% \mathrm{CI},-87.1$ to $-9.7, P=.008)$. We observed that the younger age group had a $37.5 \%$ prevalence of elevated triglyceride levels (95\% CI, 29.1\%-45.9\%) (Table 2). Furthermore, $33.7 \%$ of men aged 18 to 34 years $(95 \%$ CI, $25.2 \%-42.1 \%$ ) satisfied the criteria for metabolic syndrome, compared with $57.3 \%$ of men aged 55 years or older ( $95 \%$ CI, $47.4 \%-67.3 \%)$, with a significant overall association with age group $(P<.001)$.

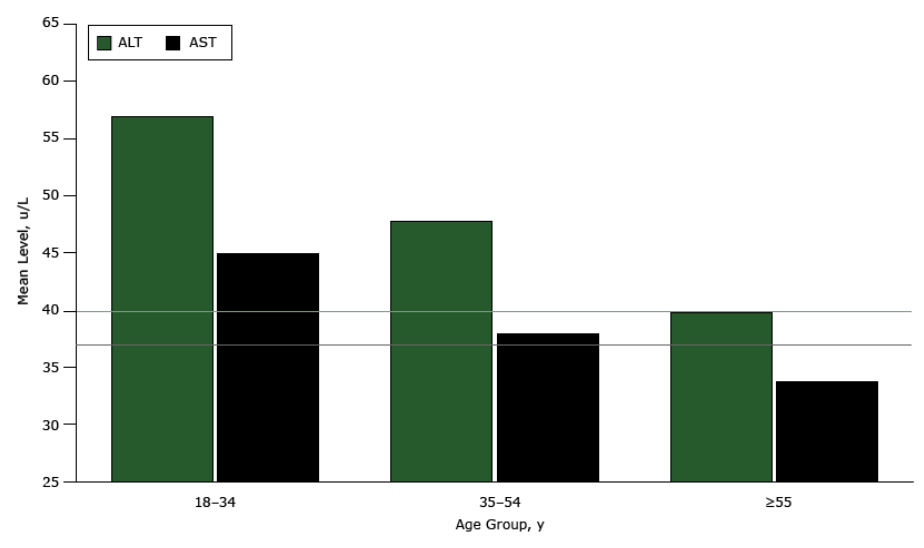

Figure 2. Mean levels of ALT and AST, by age group, male participants of the Cameron County Hispanic Cohort, 2004-2015. Mean levels of ALT and AST are highest in men younger than 35 and lower in older age groups. The upper limit of normal for ALT is $40 \mathrm{u} / \mathrm{L}$, and the upper limit of normal for AST is $37 \mathrm{u} / \mathrm{L}$ (indicated by horizontal lines on graph). Abbreviations: ALT, alanine transaminase; AST, aspartate aminotransferase.

The proportion of men with health insurance was highest in the older age group $(61.8 \%$; $95 \%$ CI, $53.0 \%-70.6 \%)$, and lowest in the younger age group $(19.2 \%$; $95 \% \mathrm{CI}, 11.7 \%-26.8 \%)$, with an overall significant association $(P<.001)$ between age group and insurance (Table 2). Having health insurance was also significantly associated with being born in the United States $(\mathrm{OR}=2.1$; 95\% CI, 1.4-3.2; data not shown), but both age group and place of birth remained independently associated with insurance status in logistic regression (data not shown).

Rates of current smoking were highest in the younger age group $(35.4 \%$; 95\% CI, $27.2 \%-43.6 \%)$ and lowest in the older age group $(19.4 \%$; $95 \%$ CI, $12.9 \%-25.8 \%)$, with an overall significant association with age $(P=.006)$. Multiple comparisons indicated that current smoking prevalence was significantly higher in the younger group than in the older group (OR [older vs younger] $=0.4$; $95 \%$ CI, 0.2-0.7) but similar to the middle group. Overall history of smoking (past or present) and drinking behavior had no significant associations with age group.

\section{Discussion}

This article is among the few population-based studies of the health of Mexican American men, and it allows for evidencebased risk stratification by age in the Mexican American population. Before this study, little was known about the health needs of Mexican American men in the southern Texas-Mexico border region. Our results show strikingly adverse metabolic and behavioral outcomes in men younger than 35 years. Poor metabolic health (eg, dyslipidemia, elevated blood pressure, obesity, and prediabetes) appears to extend into the 35 to 54 years age group. Variables that tend to be associated with older age - such as hypertension, diabetes, and metabolic syndrome - were also associated with older age in this population. Mean BMI and mean waist circumference were uniform but high across all age groups. Although mounting evidence suggests that metabolic health, as opposed to obesity, is a more important indicator of cardiovascular risk $(16,23,24)$, obesity is an important predictor of several health outcomes. In this population, obesity begins in adolescence (25) and persists through middle and older age.

A relevant finding from this study was the significant burden of obesity, prediabetes, and diabetes in the younger age group. Outcomes such as obesity tend to peak during middle age in men (26), but we found a $48.9 \%$ prevalence of obesity in younger men. For comparison, the HCHS/SOL study found a $36.8 \%$ prevalence of obesity in 2,337 Mexican American men in their nationwide survey (10); our findings suggest a higher burden of obesity in Mexican American men residing on the Texas-Mexico border than in Mexican American men nationwide. We found a 34.3\% prevalence of prediabetes and $16.9 \%$ prevalence of diabetes in the younger group. Although high rates of diabetes have been documented in this population $(15,27)$, our findings indicate a high prevalence of diabetes in young men, which has not been widely addressed in the literature. Nationwide, the overall prevalence of diabetes among Mexican American men is $18.7 \%$ (28), so the prevalence of diabetes in men younger than 35 in this population is nearly as high as the nationwide average for all ages. Employing widely used cut-offs for elevated ALT and AST, we found a $70.2 \%$ prevalence of elevated LFTs in the younger group, which was similar to the prevalence for the middle-aged group and significantly higher than that for the older group. Research indicates that ALT levels may decrease slightly with age (29), but our findings were nonetheless remarkable. Given the documented high rates of nonalcoholic fatty liver disease in this cohort (30), the authors believe that this association is real and that the drivers of elevated liver enzymes in young Mexican American men warrant further study.

\footnotetext{
The opinions expressed by authors contributing to this journal do not necessarily reflect the opinions of the U.S. Department of Health and Human Services, the Public Health Service, the Centers for Disease Control and Prevention, or the authors' affiliated institutions.
} 
The younger group fares worse than the older groups in 2 other important measures: lack of health insurance and high rates of current smoking. We found that less than $20 \%$ of men younger than 35 had any health care coverage. Limited resources exist for uninsured, and especially undocumented, men to obtain affordable health care, so preventive care may not be sought by this young population. Among men in the younger age group, $51.5 \%$ had a history of smoking and $35.4 \%$ identified as current smokers. The percentage of young men with any history of smoking was higher (though not significantly) than the percentage of older men with a history of smoking $(51.5 \%$ vs $40.0 \%)$. This finding suggests that smoking initiation across generations is consistent. Both the rate of current smoking among younger men in the CCHC (35.4\%) and rate of current smoking among all men in the CCHC (28.4\%) appear to be higher than the overall rate of current smoking in US Hispanic men (17.3\%) (31).

Although poor health outcomes were not restricted to the younger group, the findings in this group provoke the greatest concern from a prevention perspective. The high prevalence of poor metabolic health outcomes in Mexican Americans is now well documented $(14,17,26)$, but the high prevalence of poor metabolic health outcomes in young men has not yet been adequately studied. Given that more than $60 \%$ of the overall male population in this region lacks health insurance and that men in general are less likely to exhibit health-seeking behavior than women (4), these data support the need for aggressive chronic disease intervention programs for young Mexican American men.

There were several limitations to this study. The data we used were cross-sectional and do not provide insight into changes in health over time or causality. Only longitudinal data will allow us to determine whether the differences in the age groups are cohort effects or whether we may see premature death in metabolically unhealthy young men, or both. Additionally, many participants declined to provide income information. Despite these limitations, we contribute to the characterization of Mexican American men's health, affirming the importance of stratified analyses of health among Hispanic men of distinct ages and ethno-regional subgroups.

There are active obesity and diabetes prevention programs in South Texas, but we suspect that men are missed by these efforts. For example, the Coordinated Approach to Child Health (CATCH) targets obesity in children and families, and "Salud y Vida" aims to prevent diabetes in people with prediabetes. However, less than $30 \%$ of participants in "Salud y Vida" are men (M. Zolezzi, University of Texas School of Public Health, written communication, 2015). Men rarely attend free exercise classes offered by the University of Texas School of Public Health (A. Davé, University of Texas School of Public Health, written com- munication, 2016). The literature corroborates these findings, suggesting that interventions should be consciously tailored toward men (32). Additionally, we suspect that vastly different approaches are needed for each age group. We believe our findings will contribute to a re-evaluation of intervention programs in the region and shape new interventions targeting men at highest risk. Our data also suggest that men in South Texas would benefit from culturally appropriate smoking cessation programs. Lower smoking rates would consequently reduce overall cardiovascular risk. By prioritizing younger men for primary prevention, we can reduce poor health behaviors (eg, poor diet, sedentary lifestyle, tobacco use) that begin in early adulthood or even before and mitigate the burden of more severe disease (eg, cardiovascular disease, diabetes, cancer) later in life.

\section{Acknowledgments}

We thank our cohort team, particularly Rocío Uribe and her team, who recruited and documented the participants. We also thank Pablo Sánchez and Israel Hernández for data management, Marcela Morris and other laboratory staff for their contributions, and Christina Villarreal and Norma Pérez-Olazarán for administrative support. We thank the Valley Baptist Medical Center in Brownsville for housing our Clinical Research Unit. This work was supported by the Center for Clinical and Translational Sciences, which is funded by National Institutes of Health Clinical and Translational Award no. UL1 TR000371 from the National Center for Advancing Translational Sciences. The content is solely the responsibility of the authors and does not necessarily represent the official views of the National Center for Advancing Translational Sciences or the National Institutes of Health. This research was approved by the Committee for the Protection of Human Subjects of the University of Texas Health Science Center at Houston as HSC-SPH-03-007-B.

\section{Author Information}

Corresponding Author: Gordon P. Watt, University of Texas School of Public Health, Brownsville Regional Campus, 1 W University Blvd, Brownsville, TX 78520. Telephone: 956-7550628. Email: Gordon.P.Watt@uth.tmc.edu.

Author Affiliations: Kristina P. Vatcheva, Belinda M. Reininger, Joseph B. McCormick, Susan P. Fisher-Hoch, University of Texas School of Public Health, Brownsville Regional Campus,

The opinions expressed by authors contributing to this journal do not necessarily reflect the opinions of the U.S. Department of Health and Human Services, the Public Health Service, the Centers for Disease Control and Prevention, or the authors' affiliated institutions. 
Brownsville, Texas; Derek M. Griffith, Institute for Research on Men's Health, Vanderbilt University, Nashville, Tennessee; Laura Beretta, Department of Molecular and Cellular Oncology, The University of Texas, MD Anderson Cancer Center, Houston, Texas; Michael B. Fallon, Division of Gastroenterology, Hepatology, and Nutrition, The University of Texas Health Science Center at Houston Medical School, Houston, Texas.

\section{References}

1. Centers for Disease Control and Prevention, Division of Diabetes Translation. National diabetes statistics report, 2014. p. 12. http://www.cdc.gov/diabetes/pubs/statsreport14/ national-diabetes-report-web.pdf. Accessed March 9, 2015.

2. Henao-Martínez AF, Castillo-Mancilla JR. The Hispanic HIV epidemic. Curr Infect Dis Rep 2013;15(1):46-51.

3. Ramirez AG, Suarez L, Chalela P, Talavera GA, Marti J, Trapido EJ, et al. Cancer risk factors among men of diverse Hispanic or Latino origins. Prev Med 2004;39(2):263-9.

4. MacNaughton NS. Health disparities and health-seeking behavior among Latino men: a review of the literature. J Transcult Nurs 2008;19(1):83-91.

5. Miniño AM. Death in the United States, 2011. National Center for Health Statistics data brief, report no. 115; 2013. p. 8. http:/ /www.cdc.gov/nchs/data/databriefs/db115.pdf. Accessed October 8, 2015.

6. Enewold L, Horner M-J, Shriver CD, Zhu K. Socioeconomic disparities in colorectal cancer mortality in the United States, 1990-2007. J Community Health 2014;39(4):760-6.

7. Smedley BD, Stith AY, Nelson AR. Unequal treatment: confronting racial and ethnic disparities in healthcare. Washington (DC): National Academies Press; 2003.

8. Aguirre-Molina M, Pond A. Latino access to primary and preventive health services: barriers, needs, and policy implications. New York (NY): Columbia University; 2003.

9. Carter-Pokras P, Fischer A. Improvements in Latino health data. In: Aguirre-Molina M, Borrel LN, Vega W, editors. Health issues in Latino males: a social and structural approach. New Brunswick (NJ): Rutgers University Press; 2010. p. 53-64.

10. Daviglus ML, Talavera GA, Avilés-Santa ML, Allison M, Cai $\mathrm{J}$, Criqui $\mathrm{MH}$, et al. Prevalence of major cardiovascular risk factors and cardiovascular diseases among Hispanic/Latino individuals of diverse backgrounds in the United States. JAMA 2012;308(17):1775-84.

11. Kallwitz ER, Daviglus ML, Allison MA, Emory KT, Zhao L, Kuniholm MH, et al. Prevalence of suspected nonalcoholic fatty liver disease in Hispanic/Latino individuals differs by heritage. Clin Gastroenterol Hepatol 2015;13(3):569-76.
12. University of North Carolina at Chapel Hill. Hispanic Community Health Study/Study of Latinos; 2015. https:// www2.cscc.unc.edu/hchs/view/biblio/year. Accessed July 11, 2016.

13. Clark S. Census Bureau: Brownsville poorest city in U.S. Brownsville (TX): Brownsville Herald; 2013November 7. http://www.brownsvilleherald.com/news/local/article b630f374-475c-11e3-a86e-001a4bcf6878.html. Accessed July 11, 2016.

14. Fisher-Hoch SP, Rentfro AR, Salinas JJ, Pérez A, Brown HS, Reininger BM, et al. Socioeconomic status and prevalence of obesity and diabetes in a Mexican American community, Cameron County, Texas, 2004-2007. Prev Chronic Dis 2010; 7(3):A53.

15. Fisher-Hoch SP, Vatcheva KP, Laing ST, Hossain MM, Rahbar MH, Hanis CL, et al. Missed opportunities for diagnosis and treatment of diabetes, hypertension, and hypercholesterolemia in a Mexican American population, Cameron County Hispanic Cohort, 2003-2008. Prev Chronic Dis 2012;9:110298.

16. Laing ST, Smulevitz B, Vatcheva KP, Rahbar MH, Reininger B, McPherson DD, et al. Subclinical atherosclerosis and obesity phenotypes among Mexican Americans. J Am Heart Assoc 2015;4(3):e001540.

17. Pan J-J, Qu H-Q, Rentfro A, McCormick JB, Fisher-Hoch SP, Fallon MB. Prevalence of metabolic syndrome and risks of abnormal serum alanine aminotransferase in Hispanics: a population-based study. PLoS One 2011;6(6):e21515.

18. Perez A, Anzaldua M, McCormick J, Fisher-Hoch S. High frequency of chronic end-stage liver disease and hepatocellular carcinoma in a Hispanic population. J Gastroenterol Hepatol 2004;19(3):289-95.

19. Salinas J, McCormick JB, Rentfro A, Hanis C, Hossain MM, Fisher-Hoch SP. The missing men: high risk of disease in men of Mexican origin. Am J Men Health 2011;5(4):332-40.

20. American Diabetes Association. Diagnosis and classification of diabetes mellitus. Diabetes Care 2010;33(Suppl 1):S62-9.

21. Grundy SM, Becker D, Clark LT, Cooper RS, Denke MA, Howard WJ, et al.Third report of the National Cholesterol Education Program (NCEP) Expert Panel on Detection, Evaluation, and Treatment of High Blood Cholesterol in Adults (Adult Treatment Panel III). p. 284. Report no. 025215; 2002. http://www.nhlbi.nih.gov/files/docs/resources/ heart/atp3full.pdf.

22. National Institutes of Health, National Institute on Alcohol Abuse and Alcoholism. What's at-risk or heavy drinking? http://rethinkingdrinking.niaaa.nih.gov/How-much-is-toomuch/Is-your-drinking-pattern-risky/Whats-At-Risk-OrHeavy-Drinking.aspx. Accessed April 18, 2016.

\footnotetext{
The opinions expressed by authors contributing to this journal do not necessarily reflect the opinions of the U.S. Department of Health and Human Services, the Public Health Service, the Centers for Disease Control and Prevention, or the authors' affiliated institutions.
} 
23. Wildman RP, McGinn AP, Lin J, Wang D, Muntner P, Cohen $\mathrm{HW}$, et al. Cardiovascular disease risk of abdominal obesity vs. metabolic abnormalities. Obesity (Silver Spring) 2011; 19(4):853-60.

24. Wu S, Fisher-Hoch SP, Reininger BP, Vatcheva KP, McCormick JB. Metabolic health has greater impact on diabetes than simple overweight/obese in Mexican-Americans. J Diabetes Res 2016;2015:2016.

25. Rentfro AR, Nino JC, Pones RM, Innis-Whitehouse W, Barroso CS, Rahbar MH, et al. Adiposity, biological markers of disease, and insulin resistance in Mexican American adolescents, 2004-2005. Prev Chronic Dis 2011;8(2):A40.

26. Kaplan RC, Avilés-Santa ML, Parrinello CM, Hanna DB, Jung M, Castañeda SF, et al. Body mass index, sex, and cardiovascular disease risk factors among Hispanic/Latino adults: Hispanic community health study/study of Latinos. J Am Heart Assoc 2014;3(4):e000923.

27. Brown HS 3d, Wilson KJ, Pagán JA, Arcari CM, Martinez M, Smith K, et al. Cost-effectiveness analysis of a community health worker intervention for low-income Hispanic adults with diabetes. Prev Chronic Dis 2012;9:120074.

28. Schneiderman N, Llabre M, Cowie CC, Barnhart J, Carnethon M, Gallo LC, et al. Prevalence of diabetes among Hispanics/ Latinos from diverse backgrounds: the Hispanic Community Health Study/Study of Latinos (HCHS/SOL). Diabetes Care 2014;37(8):2233-9.

29. Goh GB-B, Pagadala MR, Dasarathy J, Unalp-Arida A, Pai RK, Yerian L, et al. Age impacts ability of aspartate-alanine aminotransferase ratio to predict advanced fibrosis in nonalcoholic Fatty liver disease. Dig Dis Sci 2015; 60(6):1825-31.

30. Pan J-J, Fisher-Hoch SP, Chen C, Feldstein AE, McCormick JB, Rahbar $\mathrm{MH}$, et al. Burden of nonalcoholic fatty liver disease and advanced fibrosis in a Texas Hispanic community cohort. World J Hepatol 2015;7(11):1586-94.

31. Jamal A, Agaku IT, O'Connor E, King BA, Kenemer JB, Neff L. Current cigarette smoking among adults-United States, 2005-2013. MMWR Morb Mortal Wkly Rep 2014; 63(47):1108-12.

32. Robertson LM, Douglas F, Ludbrook A, Reid G, van Teijlingen E. What works with men? A systematic review of health promoting interventions targeting men. BMC Health Serv Res 2008;8(1):141.

\footnotetext{
The opinions expressed by authors contributing to this journal do not necessarily reflect the opinions of the U.S. Department of Health and Human Services, the Public Health Service, the Centers for Disease Control and Prevention, or the authors' affiliated institutions.
} 


\section{Tables}

Table 1. Descriptive Statistics of Men in the Cameron County Hispanic Cohort ( $=945), 2004-2015$

\begin{tabular}{|c|c|}
\hline Participant Characteristic & Value $^{a}$ \\
\hline Mean age, y (SE) $(n=945)$ & $44.3(1.0)$ \\
\hline Mean years in Brownsville (SE) $(n=945)$ & $28.2(1.9)$ \\
\hline Mean weight, kg (SE) $(n=945)$ & $90.3(1.0)$ \\
\hline Mean height, $\mathrm{cm}(\mathrm{SE})(\mathrm{n}=945)$ & $170.7(0.3)$ \\
\hline Mean waist circumference, $\mathrm{cm}(\mathrm{SE})(\mathrm{n}=945)$ & $105.2(0.7)$ \\
\hline Mean waist-to-hip ratio (SE) $(n=945)$ & $1.0(0)$ \\
\hline Mean body mass index, $\mathrm{kg} / \mathrm{m}^{2}(\mathrm{SE})(\mathrm{n}=945)$ & $30.9(0.3)$ \\
\hline \multicolumn{2}{|l|}{ Marital status $(n=944)$} \\
\hline Single/never married & 21.6 \\
\hline Married & 71.5 \\
\hline Divorced/separated & 5.9 \\
\hline Widowed & 1.1 \\
\hline \multicolumn{2}{|l|}{ Insurance $^{b}(n=944)$} \\
\hline No insurance & 63.6 \\
\hline Insurance & 36.3 \\
\hline \multicolumn{2}{|l|}{ Employment $(n=944)$} \\
\hline Retired & 15.2 \\
\hline Full-time & 46.9 \\
\hline Part-time & 14.7 \\
\hline Unemployed & 18.9 \\
\hline Not in workforce & 4.4 \\
\hline \multicolumn{2}{|l|}{ Place of birth $(n=945)$} \\
\hline United States & 48.0 \\
\hline Mexico & 50.4 \\
\hline Other & 1.6 \\
\hline \multicolumn{2}{|l|}{ Education level $(n=945)$} \\
\hline Completed high school & 58.3 \\
\hline
\end{tabular}

Abbreviation: SE, standard error.

a All statistics weighted. Percentages may not reflect the expected value due to sampling weights and design-based analyses. Values expressed as percentages, unless otherwise indicated.

b "Insurance" includes both public and private coverage of any type.

c Defined as an affirmative response to, "Have you ever smoked more than 100 cigarettes in your entire life?"

"Defined as affirmative responses to 1) "Have you ever smoked more than 100 cigarettes in your entire life?" and 2) "Do you now smoke cigarettes?"

e Defined as alanine transaminase $>40 \mathrm{u} / \mathrm{L}$ and/or aspartate aminotransferase $>37 \mathrm{u} / \mathrm{L}$.

${ }^{f}$ According to American Diabetes Association 2010 Diagnostic Guidelines (20).

${ }^{g}$ Calculated low-density lipoprotein cholesterol levels.

$\mathrm{h}$ Defined as systolic blood pressure $\geq 130 \mathrm{~mm} \mathrm{Hg}$ or diastolic blood pressure $\geq 85 \mathrm{~mm} \mathrm{Hg}$ or currently taking antihypertensive medication.

${ }^{i}$ According to Adult Treatment Panel III (21).

(continued on next page)

The opinions expressed by authors contributing to this journal do not necessarily reflect the opinions of the U.S. Department of Health and Human Services, the Public Health Service, the Centers for Disease Control and Prevention, or the authors' affiliated institutions. 
(continued)

Table 1. Descriptive Statistics of Men in the Cameron County Hispanic Cohort $(N=945), 2004-2015$

\begin{tabular}{|c|c|}
\hline Participant Characteristic & Value $^{a}$ \\
\hline Did not complete high school & 41.7 \\
\hline \multicolumn{2}{|l|}{ History of smoking $(n=945)$} \\
\hline Yes & 54.2 \\
\hline No & 45.8 \\
\hline \multicolumn{2}{|l|}{ Current smoker $^{d}(n=945)$} \\
\hline Yes & 28.4 \\
\hline No & 71.6 \\
\hline \multicolumn{2}{|l|}{ Drinking $(n=944)$} \\
\hline Never & 39.7 \\
\hline Sometimes & 60.3 \\
\hline \multicolumn{2}{|c|}{ Heavy drinking (drinks/wk) $(n=945)$} \\
\hline Yes $(>14)$ & 7.3 \\
\hline No $(\leq 14)$ & 92.7 \\
\hline \multicolumn{2}{|c|}{ Elevated liver enzymes $^{\mathrm{e}}(\mathrm{n}=945)$} \\
\hline No & 35.6 \\
\hline Yes & 64.4 \\
\hline \multicolumn{2}{|c|}{ Body mass index categories $\left(\mathrm{kg} / \mathrm{m}^{2}\right)(\mathrm{n}=945)$} \\
\hline Not obese $(\leq 30)$ & 50.1 \\
\hline Obese (>30) & 49.9 \\
\hline \multicolumn{2}{|l|}{ Diabetes categories $^{f}(n=945)$} \\
\hline Normal & 35.9 \\
\hline Prediabetes & 37.3 \\
\hline Diabetes & 26.8 \\
\hline \multicolumn{2}{|c|}{ Hypertriglyceridemia $(\mathrm{mg} / \mathrm{dL})(\mathrm{n}=945)$} \\
\hline No $(\leq 150)$ & 52.5 \\
\hline Yes (>150) & 47.5 \\
\hline
\end{tabular}

High-density lipoprotein cholesterol $(\mathrm{mg} / \mathrm{dL})(\mathrm{n}=945)$

Abbreviation: SE, standard error.

${ }^{a}$ All statistics weighted. Percentages may not reflect the expected value due to sampling weights and design-based analyses. Values expressed as percentages, unless otherwise indicated.

b "Insurance" includes both public and private coverage of any type.

c Defined as an affirmative response to, "Have you ever smoked more than 100 cigarettes in your entire life?"

"Defined as affirmative responses to 1) "Have you ever smoked more than 100 cigarettes in your entire life?" and 2) "Do you now smoke cigarettes?"

e Defined as alanine transaminase $>40 \mathrm{u} / \mathrm{L}$ and/or aspartate aminotransferase $>37 \mathrm{u} / \mathrm{L}$.

${ }^{f}$ According to American Diabetes Association 2010 Diagnostic Guidelines (20).

g Calculated low-density lipoprotein cholesterol levels.

$\mathrm{h}$ Defined as systolic blood pressure $\geq 130 \mathrm{~mm} \mathrm{Hg}$ or diastolic blood pressure $\geq 85 \mathrm{~mm} \mathrm{Hg}$ or currently taking antihypertensive medication.

i According to Adult Treatment Panel III (21).

(continued on next page)

The opinions expressed by authors contributing to this journal do not necessarily reflect the opinions of the U.S. Department of Health and Human Services, the Public Health Service, the Centers for Disease Control and Prevention, or the authors' affiliated institutions. 
(continued)

Table 1. Descriptive Statistics of Men in the Cameron County Hispanic Cohort ( $\mathrm{N}=945), 2004-2015$

\begin{tabular}{|l|r|}
\hline Participant Characteristic & Value $^{\text {a }}$ \\
\hline Normal $(\geq 40)$ & 59.8 \\
\hline Low $(<40)$ & 40.2 \\
\hline Low
\end{tabular}

Low-density lipoprotein cholesterol ${ }^{\mathrm{g}}(\mathrm{mg} / \mathrm{dL})(\mathrm{n}=945)$

\begin{tabular}{|l|r|}
\hline Normal $(\leq 160)$ & 92.7 \\
\hline Elevated $(>160)$ & 7.3 \\
\hline
\end{tabular}

Hypertension $^{\mathrm{h}}(\mathrm{n}=945)$

\begin{tabular}{|l|l|}
\hline No & 66.1 \\
\hline$Y e s$ & 33.9 \\
\hline
\end{tabular}

Yes

Metabolic syndrome $e^{i}(n=945)$

\begin{tabular}{|l|l|l|}
\hline No & 56.0 \\
\hline Yes & 44.0 \\
\hline
\end{tabular}

Abbreviation: SE, standard error.

${ }^{a}$ All statistics weighted. Percentages may not reflect the expected value due to sampling weights and design-based analyses. Values expressed as percentages, unless otherwise indicated.

b "Insurance" includes both public and private coverage of any type.

c Defined as an affirmative response to, "Have you ever smoked more than 100 cigarettes in your entire life?"

d Defined as affirmative responses to 1) "Have you ever smoked more than 100 cigarettes in your entire life?" and 2) "Do you now smoke cigarettes?"

e Defined as alanine transaminase $>40 \mathrm{u} / \mathrm{L}$ and/or aspartate aminotransferase $>37 \mathrm{u} / \mathrm{L}$.

${ }^{f}$ According to American Diabetes Association 2010 Diagnostic Guidelines (20).

g Calculated low-density lipoprotein cholesterol levels.

${ }^{\mathrm{h}}$ Defined as systolic blood pressure $\geq 130 \mathrm{~mm} \mathrm{Hg}$ or diastolic blood pressure $\geq 85 \mathrm{~mm} \mathrm{Hg}$ or currently taking antihypertensive medication.

${ }^{i}$ According to Adult Treatment Panel III (21). 
Table 2. Comparison of Variables, by Age Group, of Men in the Cameron County Hispanic Cohort (N = 945), 2004-2015

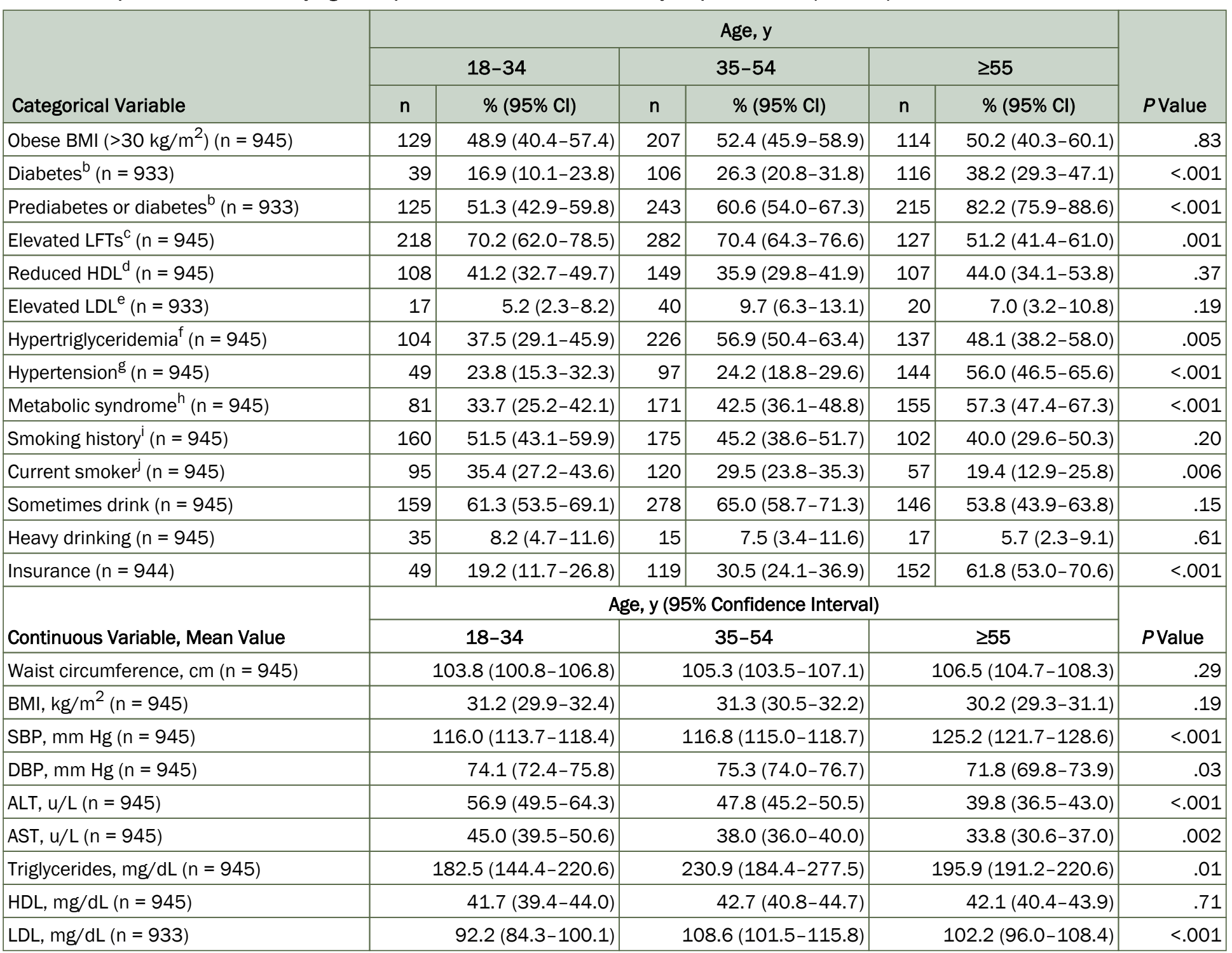

Abbreviations: ALT, alanine transaminase; AST, aspartate aminotransferase; BMI, body mass index; Cl, confidence interval; DBP, diastolic blood pressure; HDL, high-density lipoprotein cholesterol; LDL, low-density lipoprotein cholesterol; LFTs, liver function tests; SBP, systolic blood pressure.

${ }^{a}$ All statistics weighted. Percentages may not reflect the expected result due to sampling weights and design-based analyses.

${ }^{\mathrm{b}}$ According to American Diabetes Association 2010 Diagnostic Guidelines (20).

${ }^{\mathrm{c}}$ Defined as ALT $>40 \mathrm{u} / \mathrm{L}$ and/or AST $>37 \mathrm{u} / \mathrm{L}$.

d Defined as $<40 \mathrm{mg} / \mathrm{dL}$.

e Defined as LDL $>160 \mathrm{mg} / \mathrm{dL}$.

${ }^{f}$ Defined as triglyceride levels $>150 \mathrm{mg} / \mathrm{dL}$.

g Defined as systolic blood pressure $\geq 130 \mathrm{~mm} \mathrm{Hg}$ or diastolic blood pressure $\geq 85 \mathrm{~mm} \mathrm{Hg}$ or taking antihypertensive medication.

${ }^{\mathrm{h}}$ According to Adult Treatment Panel III (21).

'Defined as an affirmative response to, "Have you ever smoked more than 100 cigarettes in your entire life?"

j Defined as affirmative responses to 1) "Have you ever smoked more than 100 cigarettes in your entire life?" and 2) "Do you now smoke cigarettes?"

The opinions expressed by authors contributing to this journal do not necessarily reflect the opinions of the U.S. Department of Health and Human Services, the Public Health Service, the Centers for Disease Control and Prevention, or the authors' affiliated institutions. 
Table 3. Multiple Comparison Analysis of Variables, by Age Group, of Men in the Cameron County Hispanic Cohort (N = 945), 2004-2015

\begin{tabular}{|l|l}
\hline Categorical Variable & Odds Ratio $^{a}$ \\
\hline
\end{tabular}

Diabetes $^{\text {b }}$

\begin{tabular}{|l|r|}
\hline $18-34$ & 1 [Reference] \\
\hline $35-54$ & $1.8(1.0$ to 3.1) \\
\hline$\geq 55$ & $3.0(1.7$ to 5.6)
\end{tabular}

Prediabetes or diabetes

18-34

1 [Reference]

$35-54$

$\geq 55$

1.5 (0.9 to 2.3)

4.4 (2.6 to 7.4 )

Elevated liver function tests ${ }^{c}$

18-34

35-54

$\geq 55$

$\mid$

\begin{tabular}{rr|} 
& 1 [Reference] \\
\hline & $1.0(0.6$ to 1.6$)$ \\
$0.4(0.3$ to 0.8$)$
\end{tabular}

\section{Hypertriglyceridemia $^{\mathrm{d}}$}

\begin{tabular}{|l|r|}
\hline $18-34$ & 1 [Reference] \\
\hline $35-54$ & $2.2(1.4$ to 3.4$)$ \\
\hline$\geq 55$ & $1.5(0.9$ to 2.6$)$ \\
\hline
\end{tabular}

Hypertension $^{\mathrm{e}}$

18-34

1 [Reference]

$35-54$

$\geq 55$

1.0 (0.6 to 1.8$)$

Metabolic syndrome $^{f}$

\begin{tabular}{|l|r|}
\hline $18-34$ & 1 [Reference] \\
\hline $35-54$ & $1.5(0.9$ to 2.3$)$ \\
\hline$\geq 55$ & $2.6(4.5$ to 4.6$)$ \\
\hline
\end{tabular}

Health insurance

\begin{tabular}{|l|r|}
\hline $18-34$ & 1 [Reference] \\
\hline $35-54$ & $1.8(1.1$ to 3.2) \\
\hline$\geq 55$ & $6.8(3.8$ to 12.3) \\
\hline Current smokerg & \multicolumn{1}{|c}{} \\
\hline $18-34$ & 1 [Reference] \\
\hline
\end{tabular}

a Survey-weighted odds ratio generated from logistic regression.

${ }^{b}$ According to American Diabetes Association 2010 Diagnostic Guidelines (20).

${ }^{c}$ Defined as alanine transaminase $>40 \mathrm{u} / \mathrm{L}$ and/or aspartate aminotransferase $>37 \mathrm{u} / \mathrm{L}$.

d Defined as triglyceride levels $>150 \mathrm{mg} / \mathrm{dL}$.

e Defined as systolic blood pressure $\geq 130 \mathrm{~mm} \mathrm{Hg}$ or diastolic blood pressure $\geq 85 \mathrm{~mm}$ Hg or taking antihypertensive medication.

${ }^{f}$ According to Adult Treatment Panel III (21).

g Defined as affirmative responses to 1) "Have you ever smoked more than 100 cigarettes in your entire life" and 2) "Do you now smoke cigarettes?"

${ }^{\mathrm{h}}$ Bonferroni adjusted $P$ values for multiple pairwise comparisons.

i Nonsignificant after controlling for place of birth.

(continued on next page)

The opinions expressed by authors contributing to this journal do not necessarily reflect the opinions of the U.S. Department of Health and Human Services, the Public Health Service, the Centers for Disease Control and Prevention, or the authors' affiliated institutions. 
(continued)

Table 3. Multiple Comparison Analysis of Variables, by Age Group, of Men in the Cameron County Hispanic Cohort ( $\mathrm{N}=945), 2004-2015$

\begin{tabular}{|c|c|c|}
\hline Categorical Variable & Odds Ratio ${ }^{a}$ & \\
\hline $35-54$ & & $0.8(0.5$ to 1.2$)$ \\
\hline$\geq 55$ & & $0.4(0.3$ to 0.8$)$ \\
\hline Continuous Variable & Difference ( $95 \%$ Confidence Interval) & $P$ Value $^{\mathrm{h}}$ \\
\hline \multicolumn{3}{|c|}{ Systolic blood pressure, $\mathrm{mmHg}$} \\
\hline $18-34$ & \multicolumn{2}{|r|}{ Reference } \\
\hline $35-54$ & $-0.8(-4.5$ to 2.9$)$ & .99 \\
\hline$\geq 55$ & $-9.1(-14.2$ to -4.0$)$ & $<.001$ \\
\hline \multicolumn{3}{|c|}{ Diastolic blood pressure, $\mathrm{mmHg}$} \\
\hline $18-34$ & \multicolumn{2}{|r|}{ Reference } \\
\hline $35-54$ & $-1.2(-3.9$ to 1.5$)$ & .82 \\
\hline$\geq 55$ & $2.3(-1.0$ to 5.5$)$ & .28 \\
\hline \multicolumn{3}{|l|}{ Triglycerides, $\mathrm{mg} / \mathrm{dL}$} \\
\hline $18-34$ & \multicolumn{2}{|r|}{ Reference } \\
\hline $35-54$ & $-48.4(-87.1$ to -9.7$)$ & .008 \\
\hline$\geq 55$ & $-13.4(-58.4$ to 31.6$)$ & .99 \\
\hline \multicolumn{3}{|c|}{ Low-density lipoprotein cholesterol, mg/dL } \\
\hline $18-34$ & \multicolumn{2}{|r|}{ Reference } \\
\hline $35-54$ & $-16.4(-25.7$ to -7.2$)$ & $<.001$ \\
\hline$\geq 55$ & $-10.0(-20.1$ to 0.1$)$ & .05 \\
\hline \multicolumn{3}{|c|}{ Alanine transaminase levels, $\mathrm{u} / \mathrm{L}$} \\
\hline $18-34$ & \multicolumn{2}{|r|}{ Reference } \\
\hline $35-54$ & $9.1(-0.6$ to 18.9$)$ & .08 \\
\hline$\geq 55$ & $17.2(7.4$ to 27.0$)$ & $<.001$ \\
\hline \multicolumn{3}{|c|}{ Aspartate aminotransferase levels, $u / L$} \\
\hline $18-34$ & \multicolumn{2}{|r|}{ Reference } \\
\hline $35-54$ & $7.1(0.02 \text { to } 14.1)^{i}$ & $.05^{\mathrm{i}}$ \\
\hline$\geq 55$ & $11.2(3.7$ to 18.7$)$ & .001 \\
\hline
\end{tabular}

a Survey-weighted odds ratio generated from logistic regression.

${ }^{\mathrm{b}}$ According to American Diabetes Association 2010 Diagnostic Guidelines (20).

${ }^{c}$ Defined as alanine transaminase $>40 \mathrm{u} / \mathrm{L}$ and/or aspartate aminotransferase $>37 \mathrm{u} / \mathrm{L}$.

${ }^{\mathrm{d}}$ Defined as triglyceride levels $>150 \mathrm{mg} / \mathrm{dL}$.

e Defined as systolic blood pressure $\geq 130 \mathrm{~mm} \mathrm{Hg}$ or diastolic blood pressure $\geq 85 \mathrm{~mm}$ Hg or taking antihypertensive medication.

${ }^{\mathrm{f}}$ According to Adult Treatment Panel III (21).

${ }^{8}$ Defined as affirmative responses to 1) "Have you ever smoked more than 100 cigarettes in your entire life" and 2) "Do you now smoke cigarettes?"

${ }^{\mathrm{h}}$ Bonferroni adjusted $P$ values for multiple pairwise comparisons.

i Nonsignificant after controlling for place of birth.

The opinions expressed by authors contributing to this journal do not necessarily reflect the opinions of the U.S. Department of Health and Human Services, the Public Health Service, the Centers for Disease Control and Prevention, or the authors' affiliated institutions. 